\title{
Industrieklebstoffe mit funktionalem Zusatznutzen
}

$\mathrm{D}$ e Jowat $A G$ wird auf der vom 18. bis zum 21. Februar in Bad Salzuflen stattfindenden ZOW 2013 - der internationalen Zuliefermesse für Möbelindustrie \& Innenausbau - Klebstoffe vorstellen, die verschiedene funktionale Zusatznutzen wie Schwerentflammbarkeit, Glanzgrad, Oberflächenhärte und Atmungsaktivität bieten.

So sind die Klebstoffe der Produktfamilie Jowacoll, die für die Herstellung von Brandschutztüren, Wand- und Deckenpanelen beim Schiffsinnenausbau, aber auch beim Objektausbau eingesetzt werden, durch Feuerbeständigkeit bzw. Schwerentflammbarkeit gekennzeichnet.

Ebenfalls zu den Exponaten zählen farblos-transparent vernetzende Polyurethan-Hotmelts, die speziell für die Folienkaschierung entwickelt wurden. Sie tragen den Markennamen Jowatherm-Reaktant und sind in der Lage, den Glanzgrad folienkaschierter Möbelteile zusätzlich zu verbessern. Zudem ermöglicht dieser Hotmelt durch das breite Adhäsionsspektrum eine Vielfalt von Materialkombinationen und Dekorvarianten.

Präsentiert werden ferner Klebstoffe, welche die Anforderungen moderner Produktionstechniken für Möbeloberflächen erfüllen. Ein Qualitätsmerkmal ist hierbei die Oberflächenhärte von Beschichtungen. Klebstoffe der Jowat-Top-
therm-Produktfamilie punkten mit einem sehr hohen Druckwiderstand (Shore Härte) - und dies auch bei erhöhten Temperaturen. Einbußen der Oberflächenqualität, die durch Abzeichnungen in der Oberfläche zum Beispiel beim Abstapeln von frisch kaschierten Teilen entstehen können, werden so deutlich vermindert.

Zum Ausstellungsangebot gehören schließlich Klebstoffe, die für die Herstellung von Fahrzeugsitzen zum Einsatz kommen. Im Bereich der Polsterung und der Sitzbezüge werden moderne technische Textilien verwendet, die häufig als atmungsaktive, mehrlagig kaschierte Verbundmaterialien verarbeitet werden. Speziell dafür entwickelte PolyurethanHotmelts ermöglichen eine optimale Atmungsaktivität solcher Textilverbunde und sorgen für eine bestmögliche Belüftung, Wärme- und Feuchtigkeitsregulierung der Sitze.

Weitere Infos: Jowat AG, ZOW 2013, Bad Salzuflen, Halle 20, Stand B56

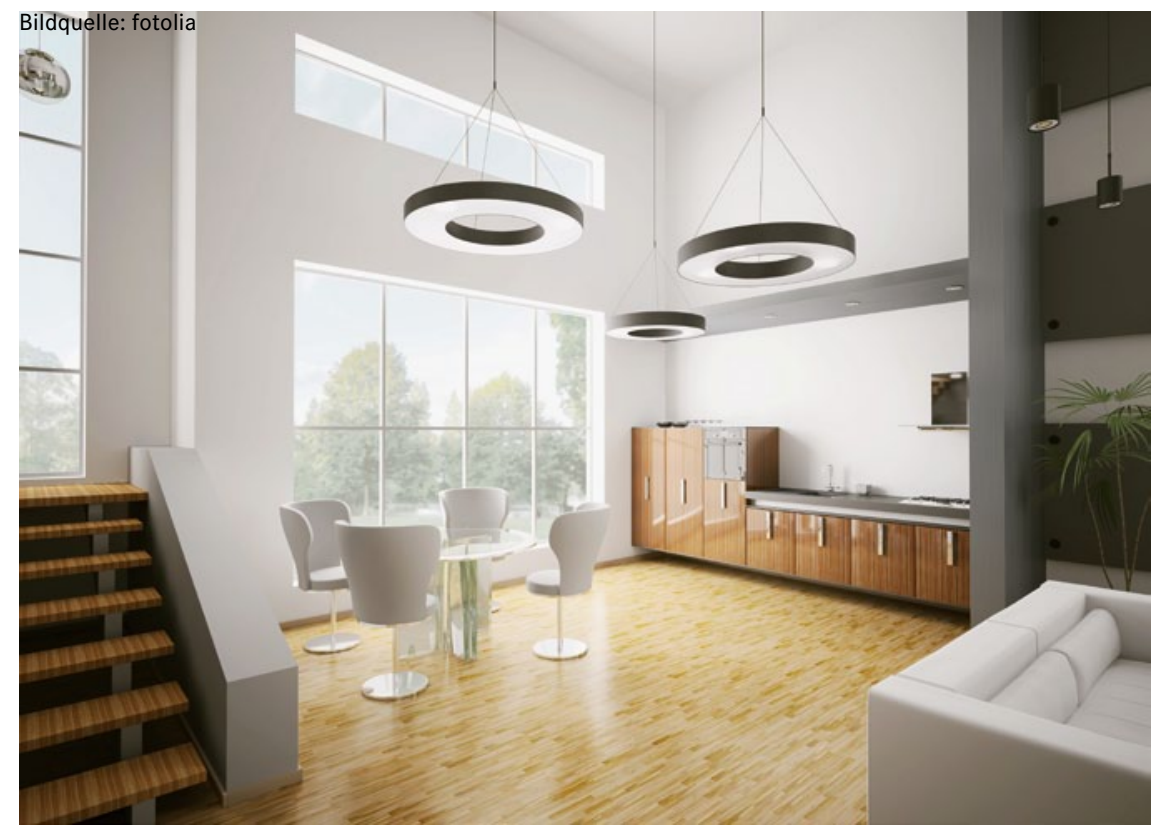

Jowat präsentiert auf der ZOW 2013 u.a. farblos-transparent vernetzende Polyurethan-Hotmelts, die in der Lage sind, den Glanzgrad folienkaschierter Möbelteile zusätzlich zu verbessern.

\section{Neues anionisches Oberflächenleimungsmittel}

$\mathrm{D}$ ie BASF hat mit Basoplast $450 \mathrm{P}$ ein neues Polymerleimungsmittel für Oberflächenanwendungen im Verpackungssegment entwickelt, das es $\mathrm{Pa}$ pierherstellern ermöglicht, ihre Kosten erheblich zu reduzieren. Gewöhnlich wurden bisher für die Herstellung von Wellpappenrohpapieren kationische Polymerleimungsmittel eingesetzt. Hierdurch be- schränkte sich allerdings die Auswahl der Färbemittel auf bestimmte Produktreihen.

Der Wechsel von kationischen Polymerleimungsmitteln zu dem neuen Mittel eröffnet Papierherstellern die Möglichkeit, die gewünschte Färbung mittels anionischen Direktfarbstoffen in der Oberfläche anzupassen und so kostengünstiger zu produzieren.
Das anionische Produkt zeigt keine Neigung zur Schaumbildung, ist zudem unempfindlich gegenüber $\mathrm{pH}$ Wert sowie Stärkeart, kann sowohl in Leim- als auch Filmpressen eingesetzt werden und ist für den Kontakt mit Lebensmitteln zugelassen.

Weitere Infos: www.basf.com. 